\title{
Improvement of Torque Production in Single-Phase Induction Motors
}

\author{
G. A. Olarinoye ${ }^{*}$, J. Yusuf, B. Jimoh \\ Department of Electrical Engineering, Ahmadu Bello University Zaria, Kaduna State, Nigeria.
}

\begin{abstract}
Existing single phase induction motors exhibit low starting torque. Moreover, during accelerating time and at steady state, they produce a significant level of torque pulsations which gives rise to noise and vibration in the machine. As part of efforts to mitigate these problems, a performance improvement strategy using a PWM inverter to drive the existing motor is implemented in MATLAB/Simulink environment in this work. The drive supplies variable voltage and phase to the auxiliary winding with the aid of a pulse width modulation (PWM) technique and a PID controller. Simulation results show the starting torque of the motor increased by $75 \%$ under the developed drive scheme. In addition, torque pulsations reduced from $1.4 \mathrm{Nm}$ peak-peak to $0.14 \mathrm{Nm}$ peak-peak at steady state. It was observed that the accelerating time reduced by $30 \%$ compared to the accelerating time under line operation. The strategy eliminates the need for series-connected capacitors thereby potentially enhancing the reliability of the motor.
\end{abstract}

KEYWORDS: Induction motor, torque pulsations, modulation, performance improvement, inverter, single-phase.

[Received April 26 2017; Revised July 8 2017; Accepted August 18 2017]

\section{INTRODUCTION}

Single phase induction motors are motors fed from a single phase power source. Power is supplied to the rotor of these motors by electromagnetic induction. The different types of single phase induction motors (SPIMs) include the split phase, shaded pole and the capacitor types. The most common of these is the capacitor-run single phase induction motor (CRSPIM). This type of SPIM has a capacitor connected in series with the auxiliary winding and its purpose is to balance the currents in the main and auxiliary windings during running conditions thereby providing quiet operation and maximum efficiency. Often times, another capacitor of higher capacitance is provided in the auxiliary winding circuit to ensure high starting torque.

This starting capacitor, however, is disconnected by a centrifugal switch after the motor attains about $75 \%$ of its rated speed. Capacitor-run single phase induction motors find application in residential, commercial and industrial centers across the globe. They are used in washing machines, dish washers, fans, refrigerators and air-conditioners just to mention a few. The problem with these motors are (i) high torque pulsations which give rise to noise and losses and (ii) low efficiency especially when used under non-rated conditions. A lot of work aimed at addressing these problems has been reported in literature.

The aspiration in most of the methods used to address these problems is the elimination of the double unbalance in supply voltage/current and in the main and auxiliary windings. Chomat and Lipo (2003) applied a half bridge inverter to supply an auxiliary winding voltage shifted by $86^{\circ}$ from the phase of the main winding voltage to achieve

*Corresponding author's e-mail address: baolarinoye@abu.edu.ng balanced flow of winding currents. Asghari and Fallah (2012) proposed an inverter - based method to produce the necessary phase shift required for motor operation. CRSPIM performance under different capacitance values was investigated in Hekmati et al. (2014).

The study focuses on a control strategy in which a parallel bidirectional switch plus a fixed capacitor was simulated to reduce torque pulsations in the motor. In this paper, effort is made to supply balanced voltages to the windings of an existing CRSPIM with a view to reducing pulsations in the electromagnetic torque produced in the motor at all operating points.

\section{CONDITION FOR ELIMINATING TORQUE PULSATION}

The average or useful torque in the single phase induction machine going by the double revolving field theory (DRFT) (Morrill, 1929; Collins et al, 1988; Kim et al, 2003) is given as;

$$
T_{a v g}=\left[I_{m}^{2}+I_{a}^{2} a^{2}\right]\left(R_{f}-R_{b}\right)+2 I_{m} I_{a} a\left(R_{f}+R_{b}\right) \sin \emptyset
$$

The pulsating component of the torque produced is given as (Morrill, 1929; Collins et al., 1988):

$$
\begin{gathered}
T_{p u l s}=\left[I_{m}^{2}\left(R_{f}-R_{b}\right)+I_{s}^{2} a^{2}\left(R_{f}-R_{b}\right) \cos 2 \emptyset-\right. \\
\left.I_{s}^{2} a^{2}\left(X_{f}-X_{b}\right) \sin 2 \emptyset\right] \cos 2 \omega t+\left[-I_{m}^{2}\left(X_{f}-X_{b}\right)-\right. \\
\left.I_{s}^{2} a^{2}\left(R_{f}-R_{b}\right) \sin 2 \emptyset-I_{s}^{2} a^{2}\left(X_{f}-X_{b}\right) \cos 2 \emptyset\right] \sin 2 \omega t
\end{gathered}
$$

where

$a$ is the effective turns ratio of the auxiliary winding to the main winding, $I_{m}$ and $I_{a}$ are the main and auxiliary winding

doi: http://dx.doi.org/10.4314/njtd.v14i2.1 
current magnitudes respectively, $\varnothing$ is the difference between the main and auxiliary winding current phase angles, $R_{f}$ and $X_{f}$ are the equivalent forward field resistance and reactance respectively while $R_{b}$ and $X_{b}$ are the equivalent backward field resistance and reactance respectively. These parameters are defined as follows (Morrill 1929; Collins et al. 1988; Jang 2013):

$$
\begin{aligned}
& R_{f}=\frac{\left[\frac{X_{m}^{2} r_{2}}{2 s}\right]}{\left[\left(\frac{r_{2}}{s}\right)^{2}+\left(X_{2}+X_{m}\right)^{2}\right]} \\
& R_{b}=\frac{\left[\frac{X_{m}^{2} r_{2}}{2(2-s)}\right]}{\left[\left(\frac{r_{2}}{(2-s)}\right)^{2}+\left(X_{2}+X_{m}\right)^{2}\right]} \\
& X_{f}=\frac{\frac{X_{m}}{2}\left[\left(\frac{r_{2}}{s}\right)^{2}+X_{2}\left(X_{2}+X_{m}\right)\right]}{\left[\left(\frac{r_{2}}{s}\right)^{2}+\left(X_{2}+X_{m}\right)^{2}\right]} \\
& X_{b}=\frac{\frac{X_{m}}{2}\left[\left(\frac{r_{2}}{(2-s)}\right)^{2}+X_{2}\left(X_{2}+X_{m}\right)\right]}{\left[\left(\frac{r_{2}}{(2-s)}\right)^{2}+\left(X_{2}+X_{m}\right)^{2}\right]}
\end{aligned}
$$

where $X_{m}, r_{2}$ and $X_{2}$ are the magnetizing reactance, rotor resistance and reactance referred to the stator. $s$ is the slip. In literature, the magnitude of the pulsating torque component is typically used to characterize the strength of the torque pulsations (Vaez-Zadeh and Langari, 2000). This magnitude is obtained from eqn (2) and is expressed as (Collins et al, 1988; Morrill, 1929):

$$
\frac{\left|T_{p u l s}\right|=}{\sqrt{\left[I_{m}^{4}+I_{a}^{4} a^{4}+2 I_{m}^{2} I_{a}^{2} a^{2} \cos 2 \varnothing\right]\left[\left(R_{f}-R_{b}\right)^{2}+\left(X_{f}-X_{b}\right)^{2}\right]}}
$$

Equation (7) suggests that the pulsating torque can be eliminated if the following expression is true;

$$
\cos 2 \emptyset=-\frac{I_{m}^{4}+I_{a}^{4} a^{4}}{2 I_{m}^{2} I_{a}^{2} a^{2}}
$$

Equation (8) constrains the magnitude of the main and auxiliary windings to the following relationship for $\varnothing$ equal $90^{\circ}$

$$
I_{m}=a I_{a}
$$

Equation (9) will be used in section $\mathrm{V}$ to compute the magnitude of the voltage which when applied to the auxiliary winding voltage could eliminate torque pulsations in the single phase motor.

\section{MODEL OF THE CRSPIM}

The model equations of the capacitor-run single phase induction machine expressed in the stationary reference frame (Ong, 1998) are given as follows;

$V_{q s}=r_{a s} i_{q s}+p \lambda_{q s}$

$V_{d s}^{\prime}=r_{b s}^{\prime} i_{d s}^{\prime}+p \lambda_{d s}^{\prime}$

$V_{b s}^{\prime}=V_{s}-V_{c}$

$$
\begin{aligned}
& i_{b s}^{\prime}=C p V_{c} \\
& V_{q r}^{\prime}=r_{r}^{\prime} i^{\prime}{ }^{\prime}-\omega_{r} \lambda_{d r}^{\prime}+p \lambda^{\prime}{ }_{q r} \\
& V_{d r}^{\prime}=r_{r}^{\prime} i_{d r}^{\prime}+\omega_{r} \lambda^{\prime}{ }_{d r}+p \lambda^{\prime}{ }_{d r} \\
& \lambda_{q s}=L_{l a s} i_{q s}+L_{\text {mas }}\left(i_{q s}+i^{\prime}{ }_{q r}\right) \\
& \lambda^{\prime}{ }_{q r}=L^{\prime}{ }_{l r} i^{\prime}{ }_{q r}+L_{m a s}\left(i_{q s}+i^{\prime}{ }_{q r}\right) \\
& \lambda_{d s}^{\prime}=L_{l b s} i_{d s}^{\prime}+L_{m a s}\left(i_{d s}^{\prime}+i^{\prime}{ }_{d r}\right) \\
& \lambda_{d r}^{\prime}=L^{\prime}{ }_{l r} i_{d r}^{\prime}+L_{m a s}\left(i_{d s}^{\prime}+i^{\prime}{ }_{d r}\right) \\
& T_{e}=\frac{P}{2} L_{m a s}\left(i^{\prime}{ }_{d r} i_{q s}-i_{{ }_{d s}}^{\prime} i_{q r}^{\prime}\right) \\
& T_{e}=\frac{2 J}{P} p \omega_{r}+T_{L}
\end{aligned}
$$

The variables and parameters are defined as follows;

$\mathrm{V}_{\mathrm{s}}$ - $\quad$ Supply Voltage.

$V_{q s}$ - Voltage applied across the main winding

$V_{d s^{-}}^{\prime} \quad$ Voltage applied across the auxiliary winging referred to main winding

$i_{q s}$ - Current in the main winding

$i_{d s}^{\prime}$ - Current in the auxiliary winding referred to main winding

$\lambda_{q s}-\quad$ Flux linkage of the main winding

$\lambda_{d s}^{\prime}$ - Flux linkage of the auxiliary winding referred to main winding.

$V_{q r^{-}}^{\prime} \quad$ Voltage applied across the $\mathrm{q}-$ axis rotor winding referred to main winding

$V_{d r^{-}}^{\prime} \quad$ Voltage applied across the $\mathrm{d}-$ axis rotor winding referred to main winding

$i_{q r}^{\prime}$ - Current in the $\mathrm{q}-$ axis rotor winding referred to the main winding

$i_{d r}^{\prime}$ - Current in the $\mathrm{d}-$ axis rotor winding referred to main winding

$\lambda_{q r}^{\prime}$ - Flux linkage of the $\mathrm{q}-$ axis rotor winding referred to the main winding.

$\lambda_{d r}^{\prime}$ - Flux linkage of the $\mathrm{d}-$ axis rotor winding referred to main winding

$r_{q s}$ - Resistance of the running winding

$r_{d s}^{\prime}$ - Resistance of the starting winding referred to main winding.

$r_{r}^{\prime}-\quad$ Resistance of the rotor windings referred to main winding

$w_{r}-\quad$ Rotor speed

$L_{m q^{-}}$Mutual inductance between the $\mathrm{q}-$ axis stator and rotor windings

$L_{m d}^{\prime}$ - Mutual inductance between the $\mathrm{d}$ - axis stator and rotor windings referred to main winding.

$L_{l q s}$ - Leakage inductance of the main winding

$L_{l d s}^{\prime}$ - Leakage inductance of the auxiliary winding referred to main winding

$L_{l r}^{\prime}$ - Leakage inductance of the rotor winding referred to the main winding. 
$\mathrm{T}_{\mathrm{e}}-\quad$ Electromagnetic Torque

$\mathrm{P}$ - $\quad$ Number of poles on the machine

$\mathrm{J}$ - $\quad$ Total inertia of the machine

$\mathrm{T}_{\mathrm{L}}$ - Load torque

$p$ - Derivative operator given as $\frac{d}{d t}$

The $\mathrm{q}$ - axis stator winding represents the main winding while the $\mathrm{d}-$ axis stator winding represents the auxiliary winding. The $d-q$ axis is a fictitious axis used to simplify the derivation of the motor equations.

\section{PWM INVERTER DRIVE FOR PERFORMANCE IMPROVEMENTS}

The inverter drive comprises an inverter topology and associated controller that will enable the supply of a voltage to the auxiliary winding whose phase lead is as close to $90^{\circ}$ as possible with respect to the main winding voltage. The single phase inverter drive is shown in Figure 1. In this figure, the main ac voltage is rectified to $\mathrm{dc}$ and then the rectified dc voltage is filtered before feeding the inverter. The speed signal was used to calculate a reference voltage. This reference voltage is compared with the actual voltage supplied to the auxiliary winding and the error signal is processed by a PID controller to generate the PWM signals required to switch the devices of the inverter in order to synthesize the desired output to be injected into the auxiliary phase winding. This output is a voltage whose amplitude and phase is proportional to the machine speed in compliance with the condition for eliminating torque pulsations in the motor. The scheme was realized in MATLAB/Simulink environment. It was applied to a motor whose data is provided in Table 2 .

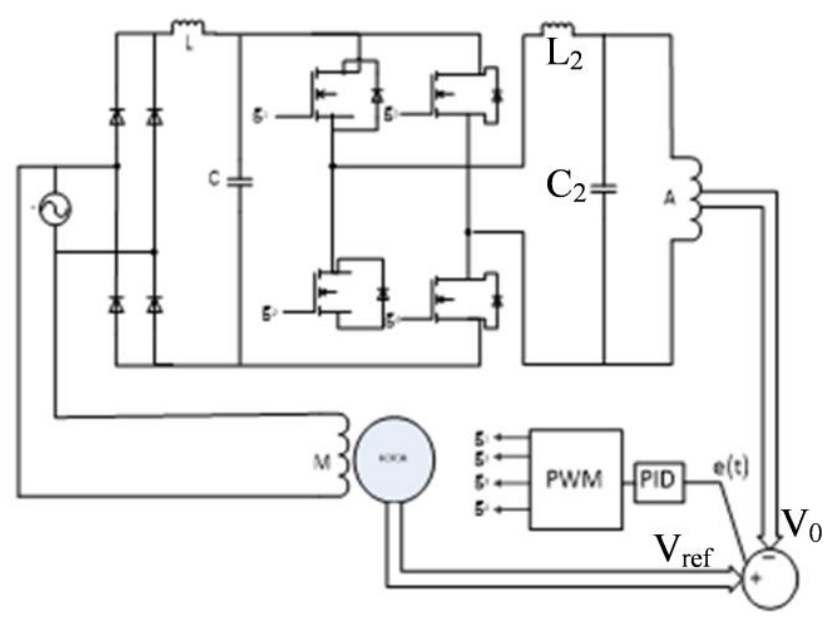

Figure 1: Pulse Width Modulated Inverter-Drive.

For the purpose of analysis, the DC side of the inverter is supplied with $200 \mathrm{~V}$ and the modulating index is chosen in such a way that the synthesized output voltage is equal to the rated voltage of the existing SPIM. The cut-off frequency, $f_{c}$ of the output filter relates to the filter values (Pawar and Kulkarni, 2015) by the following equation;

$$
f_{c}=\frac{1}{2 \pi \sqrt{L_{2} C_{2}}}
$$

$f_{c}$ is chosen as $600 \mathrm{~Hz}$ which is a compromise between eliminating higher order harmonics of the output voltage and keeping the sizes of the output inductor, $L_{2}$ and capacitor, $C_{2}$ small. $L_{2}$ is chosen as $0.04 \mathrm{mH}$ and $C_{2}$ is then calculated using eqn (22). The component values are provided in Table 1.

Table 1: DC Link Voltage and Filter Component Values for the Motor Drive

\begin{tabular}{cc}
\hline Parameters & Values \\
\hline$\left(\mathrm{V}_{\mathrm{dc}}\right)$ & $200 \mathrm{~V}$ \\
$\mathrm{~L}_{2}$ & $0.04 \mathrm{mH}$ \\
$\mathrm{C}_{2}$ & $1800 \mu \mathrm{F}$ \\
$\mathrm{f}_{\mathrm{c}}$ & $600 \mathrm{~Hz}$ \\
$\mathrm{~F}_{\mathrm{s}}$ & $2 \mathrm{kHz}$
\end{tabular}

The modulating signal in this scheme is the output of the PID controller. The inverter switches are pulse width modulated with this modulating signal and a carrier triangular wave having a frequency of $2 \mathrm{kHz}$. The switching frequency of $2 \mathrm{kHz}$ was chosen because it helps, along with the filter components, to remove the harmonics present in the output voltage of the inverter phases while minimizing the switching losses in the inverter.

\section{COMPUTATION OF REFERENCE VOLTAGE}

Using the DRFT with the SPIM equivalent circuit as given in Figure 2 (Collins et al., 1988), the voltage equations of the main and auxiliary windings may be obtained as follows;

$V_{m}=I_{m}\left[\left(R_{1 m}+R_{f}+R_{b}\right)+j\left(X_{1 m}+X_{f}+X_{b}\right)\right]+$

$I_{a}\left[a\left(X_{f}-X_{b}\right)+j\left(-a\left(R_{f}-R_{b}\right)\right)\right]$

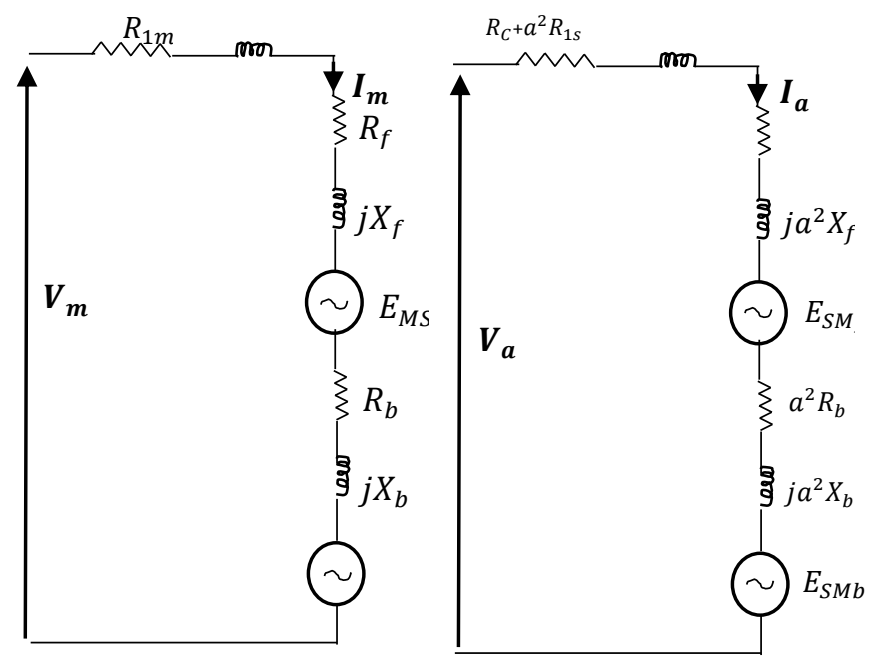

Figure 2: Equivalent Circuits of the Capacitor-Run Single-Phase Induction Machine. 
$V_{a}=I_{m}\left[-a\left(X_{f}-X_{b}\right)+a\left(R_{f}-R_{b}\right)\right]+I_{a}\left[\left(R_{1 s}+\right.\right.$
$\left.\left.a^{2}\left(R_{f}+R_{b}\right)\right)+j\left(X_{1 s}+a^{2}\left(X_{f}+X_{b}\right)\right)\right]$

$V_{m}$ is the voltage impressed on the main winding while $V_{a}$ is the voltage applied to the auxiliary winding; $I_{m}$ and $I_{a}$ are the currents flowing in the main and auxiliary windings respectively.

The expressions of the main and auxiliary winding currents are solved from eqns (23) and (24) (Collins et al., 1988). These current expressions are given as;

$$
\begin{aligned}
& I_{a}=\frac{V_{a} Z_{1}-V_{m} Z_{4}}{Z_{1} Z_{3}-Z_{2} Z_{4}}=\left|I_{a}\right| \angle \theta_{a} \\
& I_{m}=\frac{V_{m} Z_{3}-V_{a} Z_{2}}{Z_{1} Z_{3}-Z_{2} Z_{4}}=\left|I_{m}\right| \angle \theta_{m}
\end{aligned}
$$

Where

$$
\begin{aligned}
& Z_{1}=a_{1}+j b_{1} \\
& Z_{2}=a_{2}+j b_{2} \\
& Z_{3}=a_{3}+j b_{3} \\
& Z_{4}=a_{4}+j b_{4} \\
& a_{1}=r_{1 m}+R_{f}+R_{b} \\
& b_{1}=X_{1 m}+X_{f}+X_{b} \\
& a_{2}=a\left(X_{f}-X_{b}\right) \\
& b_{2}=-a\left(R_{f}-R_{b}\right) \\
& a_{3}=r_{1 a}+a^{2}\left(R_{f}+R_{b}\right) \\
& b_{3}=X_{1 a}+a^{2}\left(X_{f}+X_{b}\right) \\
& a_{4}=-a\left(X_{f}-X_{b}\right) \\
& b_{4}=a\left(R_{f}-R_{b}\right)
\end{aligned}
$$

$\theta_{a}$ and $\theta_{m}$ are the phase angles of the auxiliary and main windings respectively. The main winding voltage $V_{m}$ is taken as reference. The auxiliary winding voltage phasor has the form given as;

$\overline{V_{a}}=V_{a R}+j V_{a I}$

where $V_{a R}$ and $V_{a I}$ are the real and imaginary parts respectively. For a phase difference of $90^{\circ}$ between the phase angles of the main and auxiliary winding currents, the ratio of eqns (25) and (26) yields an expression relating the real and imaginary parts of the auxiliary winding voltage to the main winding voltage, motor parameters and the speed of the motor (Collins et al, 1988). The expression is given as;
$V_{a R}^{2}+V_{a I}^{2}+X V_{a R}+Y V_{a I}+Z=0$

where

$$
\begin{aligned}
& X=\frac{V_{m}\left[a_{1} a_{3}+a_{2} a_{4}+b_{1} b_{3}+b_{2} b_{4}\right]}{\left[-a_{1} a_{2}-b_{1} b_{2}\right]} \\
& Y=\frac{V_{m}\left[a_{1} b_{3}+a_{2} b_{4}-b_{1} a_{3}-b_{2} a_{4}\right]}{\left[-a_{1} a_{2}-b_{1} b_{2}\right]} \\
& Z=\frac{V_{m}^{2}\left[-a_{4} a_{3}-b_{3} b_{4}\right]}{\left[-a_{1} a_{2}-b_{1} b_{2}\right]}
\end{aligned}
$$

Solving the quadratic eqn (40) for $V_{a I}$ yields the following equation;

$V_{a I}=-\frac{Y\left(\left|V_{a}\right|^{2}+Z\right)}{X^{2}+Y^{2}} \pm \frac{\sqrt{Y^{2}\left(\left|V_{a}\right|^{2}+Z\right)^{2}-\left(X^{2}+Y^{2}\right)\left(\left|V_{a}\right|^{4}+\left|V_{a}\right|^{2}\left(2 Z-X^{2}\right)+Z^{2}\right)}}{X^{2}+Y^{2}}$

The reference voltage is calculated on the basis of a criteria of zero torque pulsations. Consequently, dividing eqn (26) by eqns (25) and equating to the value of the winding turn ratio in compliance with eqn (9) yields an expression for the magnitude of the reference voltage. This expression is given as follows;

$\left|V_{a}\right|=V_{m} \sqrt{\frac{\left(a_{3}+a a_{4}\right)^{2}+\left(b_{3}+a a b_{4}\right)^{2}}{\left(a_{2}+a a_{1}\right)^{2}+\left(b_{2}+a b_{1}\right)^{2}}}$

where $\left|V_{a}\right|$ is the magnitude of the voltage. The phase angle of the reference voltage, $\emptyset_{a}$ is obtained from eqns (39) and (44) and is expressed as follows;

$\emptyset_{a}=\arctan \left(\frac{V_{a I}}{V_{a R}}\right)$

The sinusoidal reference voltage, $V_{\text {ref }}$ is constructed as follows;

$$
V_{\text {ref }}=\left|V_{a}\right| \sin \emptyset_{a}
$$

The PID controller serves to adjust the inverter output voltage to follow or track this reference voltage with the consequence that the inverter output voltage leads the main winding voltage by $90^{\circ}$. It is the application of this voltage to the auxiliary winding that gives the drive the capability to reduce if not eliminate torque pulsations in the motor. This controller action emulates the function of the capacitor in the existing motor. Unlike the capacitor however, the controller action maintains quadrature phase lead across the entire motor speed. It therefore effectively replaces the capacitor as far as the inverter drive scheme is concerned.

Although Collins et al, (1988), in their analysis, provided useful relationships that points to a method of eliminating torque pulsations in single phase induction machines, they did not realize or implement any strategy to achieve the objective of eliminating torque pulsations in the machines. 
Table 2: Parameters of the CRSPIM (Ong, 1998; Krause et al., 2002; Jannati et al., 2014).

\begin{tabular}{ll}
\hline Parameters & Values \\
\hline Turn's ratio & 1.18 \\
Main winding resistance & $2.02 \Omega$ \\
Auxiliary winding resistance & $7.14 \Omega$ \\
Main winding leakage inductance & $0.0074 \mathrm{H}$ \\
Aux. winding leakage inductance & $0.0085 \mathrm{H}$ \\
Mutual Inductance & $0.1772 \mathrm{H}$ \\
Rotor resistance & $4.12 \Omega$ \\
Rotor leakage inductance & $0.056 \mathrm{H}$ \\
Run capacitive Impedance & $9-j 172 \Omega$ \\
Start capacitive Impedance & $3-j 14.5 \Omega$ \\
Moment of Inertia & $0.0146 \mathrm{kgm}$ \\
Rated voltage & $110 \mathrm{~V}$ \\
Rated power & $1 / 4 \mathrm{hp}$ \\
Rated speed & $1728 \mathrm{rpm}$ \\
Rated Torque & $1 \mathrm{Nm}$ \\
Rated frequency & $60 \mathrm{~Hz}$ \\
\hline
\end{tabular}

The drive scheme in Figure 1 was modelled and the PID controller parameters were determined by a trial and error process using the MATLAB pidtool command (Control system toolbox user's guide, 2013a). The values obtained for the proportional, integral and the derivative gains are $0.07646,4.6678$ and 0.00031312 respectively.

\section{SIMULATION RESULTS AND DISCUSSION}

Simulation results of the electromagnetic torque, reference voltage, main and auxiliary winding voltages and the speed responses are presented in this section. Figure 3 gives the dynamic torque production of the motor when the topology of Figure 1 was applied. The total simulation run time is $3 \mathrm{~s}$ and a rated load of $1 \mathrm{Nm}$ was applied at a time of $2 \mathrm{~s}$.

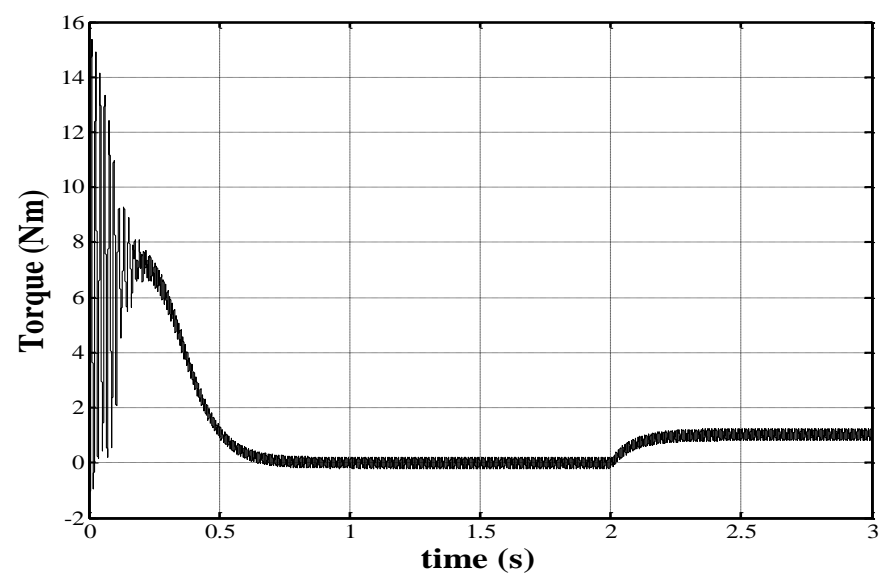

Figure 3: Dynamic Torque Production in the Inverter-driven Motor.
It can be observed in Figure 3 that the average starting torque is approximately $7 \mathrm{Nm}$ and that the torque pulsations have reduced significantly when compared to those of the line-operated capacitor-run machine given in Figure 4.

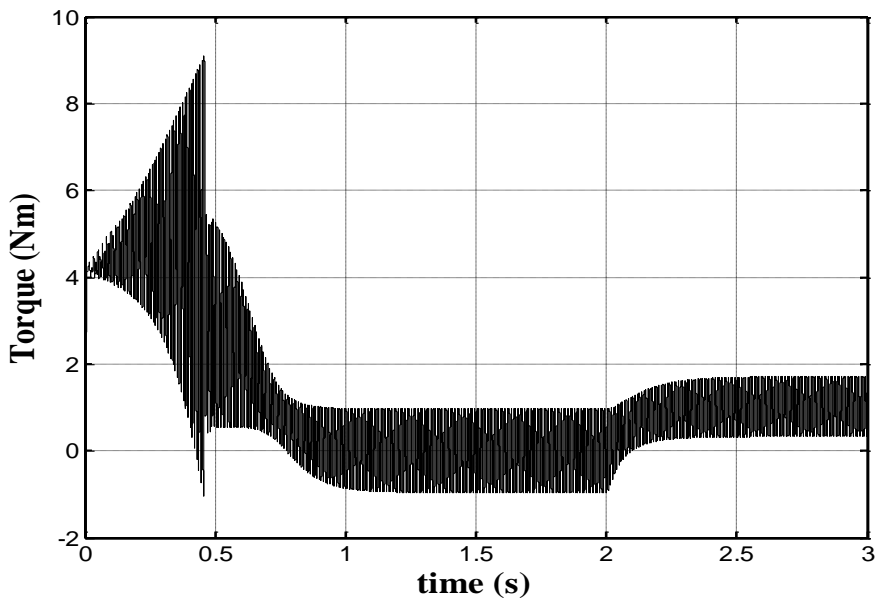

Figure 4: Dynamic Torque Production in the CRSPIM.

In Figure 4, the starting torque of the line-operated capacitor-run motor is seen to be $4 \mathrm{Nm}$. The point to note is that the inverter-driven motor has a value of starting torque that is $75 \%$ higher than that of the line operated capacitor-run motor. In addition, the peak to peak magnitude of the torque pulsations in the existing CRSPIM is $1.4 \mathrm{Nm}$ at rated load. This value was reduced to $0.14 \mathrm{Nm}$ in the inverter-driven motor as observed in Figure 3. This reduction represents an improvement of $71 \%$ over the level of torque pulsations in the existing CRSPIM. Figure 4 was obtained by solving for stator and rotor currents in eqns (10) - (19) and then using the currents to calculate the electromagnetic torque in eqn (20). (Olarinoye and Oricha, 2013).

The actual inverter output voltage is superimposed on the reference voltage in Figure 5 for ease of comparison. It can be observed that the output voltage is identical to the reference voltage. This is due to the PID controller action. The voltage is seen to vary in amplitude as motor accelerates from rest to steady state, between 0 and $3 \mathrm{~s}$.

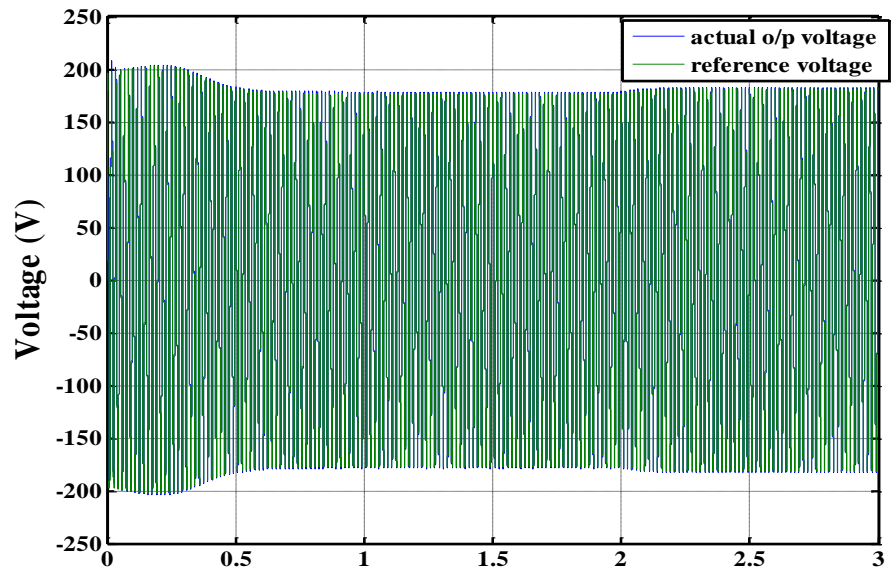

Figure 5: Actual Inverter Output Voltage and Reference Voltage vs Time. 
Figure 5 was reproduced in Figure 6 between 0 and $0.1 \mathrm{~s}$ in order to show the effect of the PID controller on the inverter output voltage.

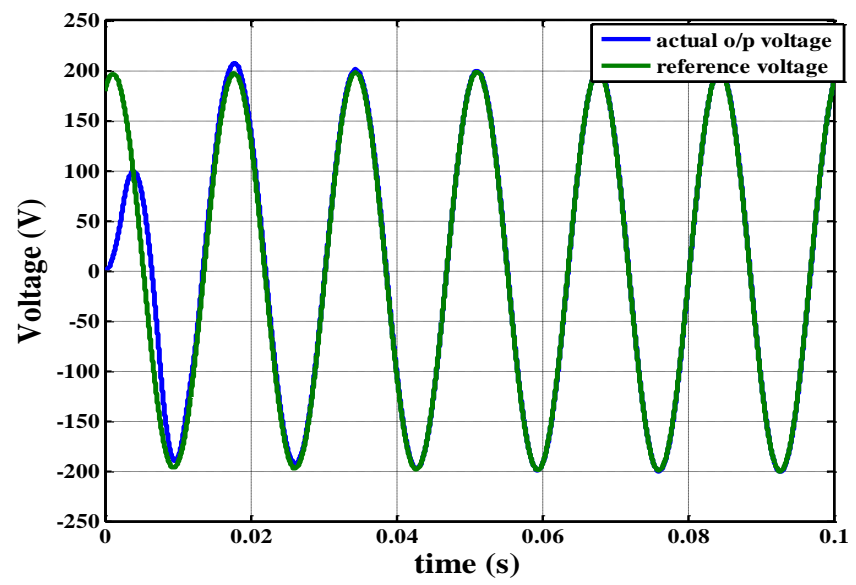

Figure 6: Reference and Actual Auxiliary Winding Voltage between 0 and 0.1s.

The actual inverter output voltage is seen to track the reference faithfully from a time of about $0.02 \mathrm{~s}$. The import of this reference tracking is seen in Figure 7.

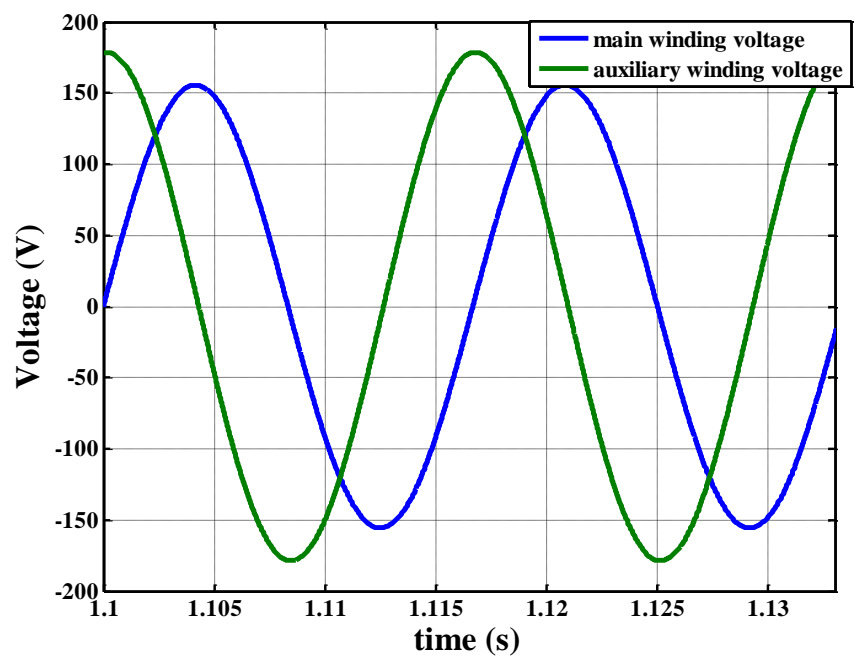

Figure 7: Main Winding Voltage and Auxiliary Winding Voltage in 2 Periods.

Figure 7 shows the main winding voltage and the auxiliary winding voltage which is the same as the inverter output voltage plotted together for the period between $1.1 \mathrm{~s}$ and 1.14 s. It can be seen that the auxiliary winding voltage leads the main winding voltage by a time phase angle of $90^{\circ}$ and that its amplitude is about 1.18 (i.e. winding turns ratio) times greater than that of the main winding voltage. This result verifies the analysis given in section $\mathrm{V}$. The controller is therefore able to command the inverter to supply balanced voltages to the stator windings of the single phase induction motor. This controller action in conjunction with the action of the pulse width modulated inverter explains the reason why there is a significant reduction in the torque pulsations of the machine as seen in Figures 3 and 4.

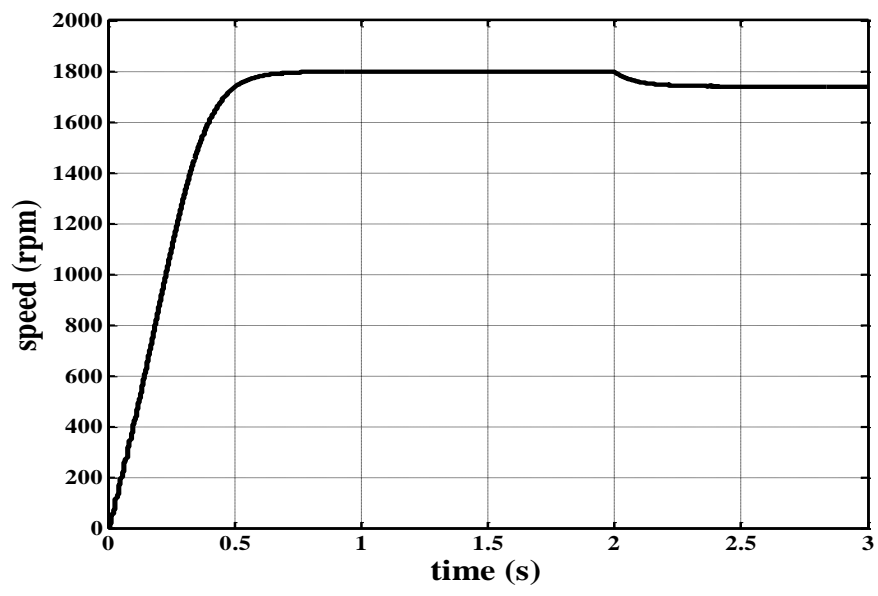

Figure 8: Speed vs Time Characteristics of the Inverter-Driven Motor.

The graph of Figure 8 shows the speed response of the inverter-driven motor. It clearly shows that the motor accelerates from rest and reaches steady state speed in $0.7 \mathrm{~s}$. The speed is seen to drop to $1730 \mathrm{rpm}$ at a time of $2 \mathrm{~s}$ after the load was applied. The gain in average starting torque increases the acceleration time of the motor with the consequence that it reaches steady state at time $0.7 \mathrm{~s}$ in Figure 8, down from 1s in Figure 9 for the line-operated capacitorrun motor. This reduction represents a 30\% improvement in the accelerating time of the motor. The broader implication of the reduction in acceleration time is that the machine runs up to steady state more efficiently.

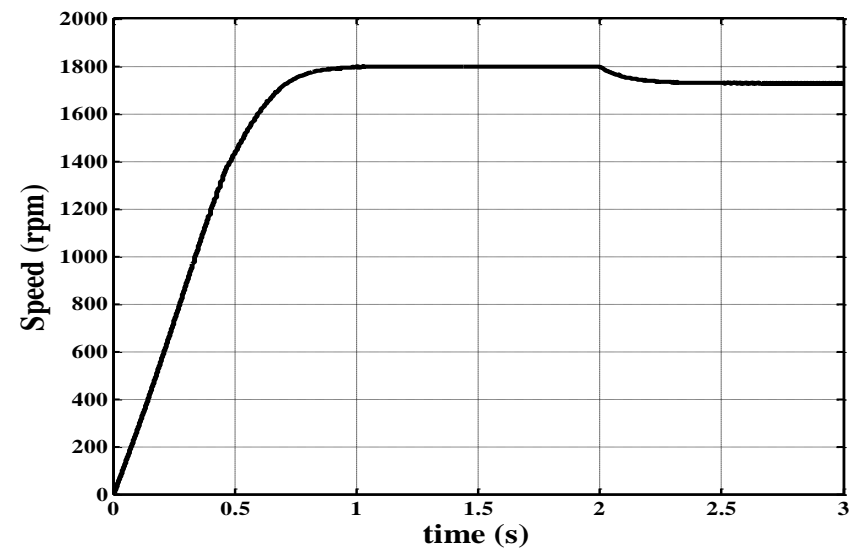

Figure 9: Speed vs Time Characteristics of the line-operated CapacitorRun Motor.

\section{CONCLUSION}

The torque performance of an existing SPIM under line operation has been compared with those of the same motor under inverter operation. In this paper, the inverter supplied voltage to the auxiliary winding with the aid of a PWM control scheme. Simulation results show a $75 \%$ increase in starting torque for a $110 \mathrm{~V}, 60 \mathrm{~Hz}$ CRSPIM. Results also show a $71 \%$ reduction in the magnitude of torque pulsations 
in the motor. These results are based on the comparison between the performances of the motor when driven by the inverter and the performances of the motor when driven conventionally by a fixed voltage source and with seriesconnected capacitors in its auxiliary winding circuit (i.e. line operation). The results show that the inverter-driven motor is

\section{REFERENCES}

Asghari, S. and Fallah, E. (2012). A New Approach for Efficiency Optimizing of Single-Phase Induction Motors. IEEE Power Electronics and Drive Systems Technology Conference (PEDSTC 2012), Tehran, Iran, 500-505.

Chomat, M. and Lipo, T. A. (2003). Adjustable-Speed Single-Phase IM Drive with Reduced Number of Switches. IEEE Transactions on Industry Applications, 39(3): 819-825.

Collins, E. R.; H. B. Puttgen and W. E. Sayle. (1988). Single-Phase Induction Motor Adjustable Speed Drive: Direct Phase Angle Control of the Auxiliary Winding Supply. IEEE Industry Applications Society Annual Meeting, Pittsburgh, U.S.A: 246-252.

Control System Toolbox User's Guide (2013a). MATLAB. The MathWorks Inc., U.S.A.

Hekmati, P.; R. Yazdanpanah, J. M. Monfared and M. Mirsalim. (2014). Adjustable Capacitor for the SinglePhase IM Performance Improvement. IEEE Power Electronics, Drive Systems and Technologies Conference (PEDSTC 2014), Tehran, Iran: 7-12.

Jang, D. H. (2013). Problems Incurred in a VectorControlled Single-Phase Induction Motor and a Proposal for a Vector-Controlled Two-Phase Induction Motor as a Replacement. IEEE Transactions on Power Electronics, 28(1): 526-536.

Jannati, M.; S. H. Asgari, N. R. N. Idris and M. J. A. Aziz. (2014). Speed Sensorless Direct Rotor Field-Oriented Control of Single-Phase Induction Motor using Extended Kalman Filter. International Journal of Power Electronics and Drive Systems, 4(4): 430-438. potentially able to operate more quietly, reliably and efficiently. It is recommended to determine the viability of the inverter drive scheme by practically implementing the scheme and conducting a cost/benefit assessment in order to determine whether or not the benefits outweigh the additional cost of inverter and its associated control scheme.

Kim, C. J.; C. Y. Choi, D. E. Lee, G. S. Choi and S. H. Baek. (2003). Torque Characteristics of Single Phase Induction Motor for Phase Control Method. Proceedings of Sixth International Conference on Electrical Machines and Systems (ICEMS 2003), China, 2: 510-513.

Krause, P. C.; O. Wasynczuk, and S. D. Sudhoff. (2002). Analysis of Electric Machinery and Drive Systems. John Wiley \& Sons, New York, U.S.A.

Morrill, W. J. (1929). The Revolving Field Theory of the Capacitor Motor. Transactions of the American Institute of Electrical Engineers, 48(2): 614-629.

Olarinoye, G. A. and Oricha, J. Y. (2013). A Method for Solving the Voltage and Torque Equations of the SplitPhase Induction Machine. Nigerian Journal of Technological Development, 10(1): 1- 6 .

Ong, C. M. (1998). Dynamic Simulation of Electric Machinery using MATLAB/SIMULINK. Prentice Hall PTR Upper Saddle River, New Jersey, U.S.A.

Pawar, S. H. and Kulkarni, A. S. (2015). Design and Analysis of Sinusoidal PWM Inverter fed Fuel Pump Motor for High Horse-Power Locomotive in MATLAB. Global Journal of Engineering Science and Researches, 2(2): 23-29.

Vaez-Zadeh, S. and Langari, H. (2000). High AverageLow Pulsating Torque Operation of Single Phase Induction Motors. Industry Applications Conference, 21(3): 1513-1518.

Veinott, C. G. (1970). Fractional and Subfractional Horsepower Electric Motors. McGraw-Hill, New York, U.S.A. 